\title{
Ectopic thyroid: etiology, pathology and management
}

\author{
Nasiru Akamnu Ibrahim, Idowu Olusegun Fadeyibi
}

Department of Surgery, Lagos State University College of Medicine and Lagos State University Teaching Hospital, Ikeja, Lagos, Nigeria

\section{INTRODUCTION}

Ectopic thyroid refers to the presence of thyroid tissue in locations other than the normal anterior neck region between the second and fourth tracheal cartilages. It is the most frequent form of thyroid dysgenesis, accounting for $48-61 \%$ of the cases. ${ }^{1}$ Prevalence of this condition is reported to be between 1 per 100,000-300,000 persons and occur one in 4,0008,000 patients with thyroid disease. ${ }^{2}$ To date, about 500 cases have been reported in the English literature mainly from Europe, Asia and America, with a small number of reports coming from Africa. Sixty-five to eighty percent of cases occurred in females. ${ }^{2}$ Although it is difficult to detect asymptomatic thyroid ectopy, post-mortem studies have suggested that $7-10 \%$ of adults may harbor asymptomatic thyroid tissue along the path of the thyroglossal duct. ${ }^{3}$ Ectopic thyroid tissue co-existing with a eutopic thyroid may be equal to that without a normally located gland. ${ }^{4}$

Key words: Aetiology, Diagnosis, Ectopic goitre, Ectopic thyroid, Hypothyroidism, Treatment

Corresponding Authors:

Ibrahim NA, Department of Surgery, Lagos State University,

College of Medicine and Lagos State University Teaching,

Hospital, P.M.B. 21266, Ikeja, Lagos, Nigeria,

E-mail: ibrahimakanmu@yahoo.com

Received 03-08-11, Revised 10-09-11, Accepted 25-09-11
Lingual thyroid is the most common type accounting for $90 \%$ of cases, while sublingual types are less frequently encountered. The sublingual types may be suprahyoid, infrahyoid or at the level of the hyoid bone. ${ }^{5}$ In 1869 , Hickman reported the first case of ectopic thyroid tumour of the base of the tongue, pressing down the epiglottis on the larynx and causing death by suffocation sixteen hours after birth. ${ }^{6}$ Other locations in the head and neck regions where ectopic thyroid tissue may be found include the trachea, ${ }^{7}$ submandibular, ${ }^{8}$ lateral cervical regions, ${ }^{9}$ axilla, ${ }^{10}$ palatine tonsils, ${ }^{11}$ carotid bifurcation, ${ }^{12}$ iris of the eye ${ }^{13}$ and pituitary gland. ${ }^{14}$ Furthermore, the presence of ectopic thyroid tissue in other places distant from the neck region has also been documented. These sites include the heart, ${ }^{15}$ ascending aorta, ${ }^{16}$ thymus, ${ }^{17}$ oesophagus, ${ }^{18}$ duodenum, ${ }^{19}$ gallbladder,${ }^{20}$ stomach bed, ${ }^{21}$ pancreas, ${ }^{22}$ mesentry of the small intestine, ${ }^{23}$ Porta Hepatis, ${ }^{24}$ adrenal gland, ${ }^{25}$ ovary, ${ }^{26}$ fallopian tube, ${ }^{27}$ uterus $^{28}$ and vagina. ${ }^{29}$

Existence of ectopic thyroid glands at two different locations is very rare. Only 27 cases of such dual ectopia have been reported in the English literature. Huang et $\mathrm{al}^{30}$ described the second case of dual ectopia with a normally located pretracheal thyroid gland. Two cases of triple ectopia have been reported, one of these by Ibrahim et al, ${ }^{31}$ where three separate ectopic thyroid masses were present in the lateral neck region with a co-existing eutopic goitre. The aim of this review is to highlight current knowledge about the aetiology, pathology and management of this condition. 


\section{EMBRYOLOGY AND AETIOLOGY}

The thyroid gland is located in the neck region in mammals. In humans it lies in the anterior neck region between the $2^{\text {nd }}$ and $5^{\text {th }}$ tracheal rings. It is the first of the body's endocrine glands to develop, on approximately the $24^{\text {th }}$ day of gestation. The gland has two diverse cell types, the thyroid follicular cells (TFCs) which produce thyroid hormones and the parafollicular or $\mathrm{C}$ cells which produce calcitonin. The cells originate from two different embryological structures: the thyroid anlage and the ultimobranchial bodies which are the sites of origin of the TFCs and $\mathrm{C}$ cells, respectively. The gland originates as a proliferation of endodermal epithelial cells on the median surface of the developing pharyngeal gut between the $1^{\text {st }}$ and $2^{\text {nd }}$ pharyngeal pouches. It lies between the tuberculum impar and the copula, at a point later indicated by the foramen caecum. The thyroid premordium penetrates the underlying mesoderm and descends, anterior to the pharyngeal gut, as a bilobed diverticulum. During the process of migration, the gland remains connected to the floor of the pharyngeal gut by the thyroglossal duct. It descends in front of the hyoid bone and the laryngeal cartilages to reach the final position in front of the trachea in the $7^{\text {th }}$ week of gestation.

Although the molecular mechanisms involved in thyroid dysgenesis are not fully known, studies have shown that mutations in regulatory genes expressed in the developing thyroid could be responsible. ${ }^{1} \mathrm{Ge}$ netic research has shown that the gene transcription factors TITF-1(Nkx2-1), Foxe1(TITF-2) and PAX-8 are essential for thyroid morphogenesis and differentiation. Mutation in these genes may be involved in abnormal migration of the thyroid. ${ }^{1,32}$ Animal studies have shown that the essential functions that TITF-1 play at later stages of thyroid development, when follicular cells reorganize themselves into follicles, require phosphorylation of the protein. ${ }^{33}$ It has also been shown in gene-targeting experiments that Foxe 1 is required for thyroid migration and that mice homozygous for Foxe1 mutations show a sublingual thyroid. ${ }^{1}$ Furthermore, the presence of a thyroid-specific regulatory element in the 5' upstream region of the PAX-8 gene has been reported. The identification of this regulatory element is believed to represent the first step in the investigation of upstream regulatory mechanisms that control Pax8 transcription during thyroid differentiation. ${ }^{34}$ In humans, more than $50 \%$ of thyroid dysgenesis cases are associated with an ectopic thyroid. However, no mutation in known genes has so far been associated with the human ectopic thyroid. ${ }^{1}$ Cases of familial thyroid ectopy where aberrant thyroid tissues were present in two members of the same family have been described. ${ }^{35}$

The majority of thyroid ectopias are located in the midline along the tract of the thyroglossal duct due to arrest of migration along the line of descent. It is assummed by some authors that TFCs derive from both a median thyroid and a lateral thyroid bud (the ultimobranchial body). It is hypothesized that aberrant thyroid tissues found in the submandibular and lateral neck regions originate from a defective lateral thyroid component that cannot migrate and fuse with the median thyroid anlage. ${ }^{1}$ Studies in animals also showed a possible link between development of major cervical arteries and relocalization of the thyroid gland. ${ }^{36}$ The dependence of thyroid morphogenesis on the development of adjacent arteries is believed to be a conserved mechanism that might have evolved to ensure efficient hormone release into circulation. Variability in the architecture of cervical vessels and branching of carotid arteries from the aortic arch might influence thyroid morphogenesis and account for some cases of ectopic thyroid tissues. ${ }^{36}$ Congenital defects of the cardiovascular system have been associated with congenital thyroid abnormalities.$^{37}$ Presence of ectopic thyroid tissues in distant locations could come about as a result of aberrant migration or heterotopic differentiation of uncommitted endodermal cells. ${ }^{24}$ An overdescent of thyroglossal duct remnants has been suggested as the cause of ectopic thyroid tissue in the mediastinum and in mid-subdiaphragmatic locations, while their presence in the genital tract could be explained through a possible mechanism of parthenogenetic development of germ cells into thyroid tissue after failure of all germ cells to migrate to the genital crest in early embryological development. ${ }^{38}$ More research is required to determine the actual cause of thyroid ectopy. Detection of the gene responsible for this condition in humans will assist early or prenatal diagnosis and better management of the disease. 


\section{PATHOLOGY}

Ectopic thyroid may become goitrous ${ }^{31}$ and may also be associated with clinically evident thyroid dysfunction, which could be either hypofunction ${ }^{39}$ or hyperfunction. ${ }^{40}$ Rarely, benign ${ }^{41}$ or malignant ${ }^{7,26}$ neoplastic changes can occur in ectopic thyroid tissue. Thyroiditis occurring in ectopic thyroid tissue has also been reported..$^{42}$ Ectopic thyroid is commonly detected during periods of increased demand for thyroid hormones, e.g. puberty and pregnancy. Increased levels of thyrotropin at these periods causes enlargement of the ectopic thyroid tissue, thereby making it clinically detectable as a mass, or following pressure symptoms. Thirty-three percent of patients diagnosed with ectopic goitre in Korea were between the ages of 10 and 20 years. ${ }^{2}$ Dossing et $\mathrm{al}^{43}$ described a case of recurrent pregnancy-related intra-tracheal thyroid growth stimulation causing upper respiratory obstructive symptoms. This was believed to be a result of the combination of increasing human chorionic gonadotropin (hCG) stimulation and borderline iodine deficiency. During pregnancy, thyroid gland size increases by an average of $30 \%$ in borderline iodine deficient regions. ${ }^{44}$ It has been speculated that epidermal growth factor could also stimulate thyroid growth..$^{43}$ Administration of lithium, a drug used in the treatment bipolar disorder, was reported to be the cause of enlargement of an ectopic lingual thyroid in a patient. ${ }^{45}$ Lithium inhibits thyroid function, leading to hypothyroidism and goitre.

Ectopic thyroid is the most common cause of congenital hypothyroidism in infants. ${ }^{2}$ In addition hypothyroidism occurs in about $33 \%$ of patients with thyroid ectopy. ${ }^{39}$ Seventy percent of patients with ectopic lingual thyroid without a co-existing eutopic thyroid tissue will develop sub-clinical hypothyroidism. This often progresses to become clinically manifest during periods of physiological stress. ${ }^{46}$ Aberration in the migratory pathways of the rudimentary thyroid that may lead to ectopy almost certainly results in inadequate blood supply to support normal thyroid function. ${ }^{47}$ While some amount of normal thyroid hormone is secreted by the ectopic gland, this may not be sufficient for higher physiological demands during puberty, pregnancy, infections and trauma. ${ }^{48}$ Studies have also suggested that iodine organification defect which is associated with thyroid ectopy could be responsible for hypothyroidism in this condition. ${ }^{49}$ It is rare for patients with ectopic thyroid to present with hypothyroidism during adulthood. ${ }^{50}$ Shakir reported the case of a 43-year old female with lingual thyroid associated with hypothyroidism and lympomatous thyroiditis..$^{51}$ Hypothyroidism was believed to have followed thyroiditis, transforming lingual thyroid into a fibrous tissue which was not sensitive to the trophic action of TSH.

Hyperthyroidism arising from ectopic thyroid tissue is less common than hypothyroidism. However, an ectopic thyroid gland with histological features of Graves' disease has been found in different locations like the base of the tongue, ${ }^{52}$ mediastinum, ${ }^{53}$ submandibular region, ${ }^{40}$ lateral neck ${ }^{54}$ and the mesentry of the small intestine. ${ }^{23}$ Some of these cases were found in patients who have had sub-total or total thyroidectomy for thyrotoxicosis. ${ }^{23,53}$ Thyrotoxicosis arising from a recurrent ectopic mediastinal thyroid was reported by Basaria et al. ${ }^{53}$ This was thought to have followed stimulation of thyroid remnant tissue by thyroid-stimulating immunoglobulins (TSI). It should be noted that ophthalmopathy can be associated with thyrotoxicosis in ectopic thyroid. ${ }^{52}$

Primary malignant transformation can occur in ectopic thyroid tissues in different locations. Papillary, follicular, mixed follicular and papillary, hurthle cell tumour and medullary carcinomas have been reported. ${ }^{55-59}$ Frequency of carcinoma in lingual thyroid is estimated to be approximately one in 100 cases with a female to male ratio ranging from $3: 1$ to 8: 1 . The majority of these tumours are described as being of the follicular type, while papillary forms comprise $23 \%$. This is in contrast to normal thyroid gland neoplasms, of which papillary tumours form the predominant form. Other variants are less frequent. ${ }^{57,60}$ Several rare tumours arising from ectopic thyroid tissues are single cases of teratoma ${ }^{61}$ and primary $\mathrm{B}$ cell lymphoma. ${ }^{62}$ Both cases occurred in a mediastinal ectopic thyroid. Rarely, malignant ectopic tumours can present with metastasis to lymph nodes.$^{55}$ Ectopic thyroid tissue located laterally in the neck was referred to in the past as 'lateral aberrant thyroid tumours' because they were thought to represent metastasis from thyroid carcinoma. However, several cases of laterally situated benign ectopic thyroid in the neck have been documented. ${ }^{9,12,31}$ 


\section{CLINICAL FEATURES}

The majority of patients with ectopic thyroid are asymptomatic, while some cases are detected incidentally. Symptoms are usually related to size and location of the ectopic gland as well as associated endocrine dysfunction. In lingual thyroid, clinical manifestations peak at a mean age of 40 years with two statistical peaks at the ages of 12.5 and 50 years. ${ }^{63}$ Common symptoms include cough, pain, dysphagia, dysphonia, dyspnoea and haemorrhage. ${ }^{2,43,63}$ Large masses can present with airway obstruction and stridor in children, while a third of patients have evidence of hypothyroidism. ${ }^{63}$ Sleep apnoea and respiratory obstruction in adult patients with lingual thyroid have been reported. ${ }^{64,65}$ A common finding on examination is enlargement of the posterior base of the tongue by a firm, midline mass. The colour can range from light pink to bright red, while the surface may be smooth or irregular. Haemorrhage or ulcerative changes may appear on laryngoscopy as a white or pink vascular mass. ${ }^{63,64}$ Sublingual or pre-laryngeal ectopic thyroid commonly presents as an anterior neck mass above, below or at the level of the hyoid bone. It is usually painless, gradually increasing in size, and may move with swallowing. Characteristically, the mass has smooth margins and is soft in consistency, mobile and non-tender. It should be differentiated from thyroglossal duct cyst, epidermal cyst, lymphadenopathy, lipoma, lymphangioma, sebaceous cyst, cystic hygroma, dermoid cyst, midline branchial cyst and neoplasms. ${ }^{66}$ Laterally placed ectopic thyroid in the neck region could present as a submandibular or lateral cervical mass. This must be differentiated from salivary gland tumours, lymphadenopathy and other subcutaneous swellings.

Intratracheal ectopic thyroid commonly present with progressive dyspnea, stridor, cough, difficulty swallowing and haemoptysis. Dyspnea in this condition may be mistaken for asthma and it might be difficult to differentiate stridor from the wheezing of asthma on physical examination. ${ }^{67}$ Intra-tracheal ectopic thyroid is visualized during direct laryngoscopy as a sub-glottic or upper tracheal wall mass covered with normal mucosa ${ }^{67}$ Intra-thoracic ectopic thyroid is usually asymptomatic and is discovered incidentally. However, it may present with cough, dyspnoea, haemoptysis and rarely with dysphagia and superior vena cava syndrome. ${ }^{68}$ Clinical presentation of intra-cardiac ectopic thyroid is commonly non-specific and cases are diagnosed during investigations for arrhythmias, embolism and obstructive symptoms. ${ }^{15}$ In other rare locations symptoms may be related to the organ involved. Adrenal ectopic thyroid could present with hypertension, ${ }^{25}$ while that in the gallbladder may present with right upper quadrant abdominal pain. ${ }^{20}$

Presentation with features of hypothyroidism occurs mainly in children. Thyroid ectopy is present in $24 \%$ of children with primary non-goitrous hypothyroidism. ${ }^{63}$ Ectopic thyroid glands in infants and young children who suffer from failure to thrive and mental retardation is often detected during routine screening and work-up for hypothyroidism. ${ }^{63}$ On the other hand, presentation with clinical features of hyperthyroidism is less common and the few reported cases were in adult and elderly patients. ${ }^{23,40,52-54}$

\section{INVESTIGATION}

Radionuclide thyroid imaging employing technetium- $99 \mathrm{~m}$ pertechnetate, iodine- 131 or iodine 123 is useful in the evaluation for ectopic thyroid. Thyroid tissue takes up the radioisotope and this helps in localizing the ectopic thyroid and at the same time in determining the presence of a eutopic thyroid gland. This is crucial to know before surgical removal of the ectopic tissue since in more than half of the patients with thyroid ectopy, no other functioning thyroid tissue exists. ${ }^{2}$ Technetium-99 pertechnetate yields better quality imaging and at the same time delivers a lower radiation burden to the body compared to iodine-131. In addition, it is widely available, waiting time is shorter following the administration of the tracer and it can be used safely in children. However, it accumulates in the background of the ectopic thyroid, including the salivary gland, making it difficult to distinguish small masses. ${ }^{2,69,70}$ Iodine- 123 is also widely used, especially in the evaluation of children, although the cost is high and its shorter half-life makes its availability more difficult. ${ }^{2}$

High resolution ultrasound scanning is generally favoured in the initial assessment, especially in patients presenting with neck masses. It is non-invasive, cost-effective and does not expose patients to ionizing radiation. At the same time it can be used to determine 
the presence of a eutopic thyroid. The sensitivity of detection of an ectopic thyroid is enhanced by the use of colour Doppler technique by demonstrating peripheral or internal colour flow signals that are reflective of hypervascularity. ${ }^{71}$ A normally located thyroid gland with normal echogenicity, contour and size confirmed on ultrasound is highly likely to be functional, this suggesting that an abnormal neck mass may be removed without the risk of postoperative hypothyroidism. ${ }^{72}$ This may obviate the need for thyroid scintigraphy to confirm the presence of a functional thyroid tissue before surgical removal of the ectopic gland. Facilities for thyroid scintigraphy may not be readily available in some resource-poor countries and ultra-sonography may be the only available imaging modality for investigating these patients.

CT scan and MRI are valuable imaging tools in the investigation of patients with ectopic thyroid. They are especially useful when a eutopic thyroid gland is not identified by ultrasound. Ectopic thyroid tissue has a characteristic uniform high attenuation on non-contrast CT, while on MRI it shows an elevated signal on T1- and T2-weighted images compared with the surrounding musculature. ${ }^{73}$ MRI is particularly useful in lingual thyroid when there is difficulty in differentiating thyroid tissue from tongue muscle. It offers less radiation exposure than CT scan. However, the cost of the procedure is higher, it requires longer imaging time and it may necessitate the use of anaesthesia in the paediatric group because of the confining nature of the imaging machine. ${ }^{73}$ Angiography has been used in the past to determine patterns of vascularization of lingual thyroid and this can help in planning surgical intervention. It can also allow the use of embolization preoperatively to decrease the risk of intraoperative haemorrhage or serve as the primary treatment modality in patients who are treated nonoperatively. ${ }^{63}$

Tissue biopsy for histology or fine needle aspiration cytology (FNAC) is especially important when malignancy is suspected. Biopsy could be taken through the endoscope in lingual and intra-tracheal ectopic glands. FNAC is one of the most accurate diagnostic methods for detection of neck masses and gives correct diagnosis in $95-97 \%$ of cases. It can assist in making a preoperative diagnosis of ectopic thyroid tissue and this helps the surgeon to decide on request about further radioisotope imaging to determine whether the mass is the only functioning thyroid tissue. ${ }^{73}$

Thyroid function tests that assess the serum levels of T3, T4, TSH and thyroglobulin are carried out in suspected cases of ectopic thyroid. Test results indicate hypothyroidism in the majority, while the rest are often euthyroid. ${ }^{2}$ Cases of hyperthyroidism may be encountered on rare occasions..$^{23,40,53}$ Plasma thyroglobulin measurement is useful in establishing the specific type of thyroid dysgenesis in infants with congenital hypothyroidism. Absence of thyroid uptake on scintigraphy with detectable serum thyroglobuling levels will indicate presence of ectopic thyroid tissue. ${ }^{74}$ Other investigations that may be required in patients with ectopic thyroid depend on the location of the gland. Echocardiography and coronary angiography may be necessary in intra-cardiac thyroid ectopy, ${ }^{15}$ while barium swallow is important in some patients presenting dysphagia. ${ }^{18}$

\section{TREATMENT}

Asymptomatic euthyroid patients with ectopic thyroid do not usually require therapy but are kept under observation. For those with symptoms, treatment depends on size of the gland, nature of symptoms, thyroid function status and histological findings. In patients with lingual, sublingual, lateral neck or intra-tracheal thyroid with hypothyroidism, suppressive therapy is administered using exogenous thyroid hormone. This suppresses the TSH level and causes reduction in the size of the gland. Euthyroid patients with mild obstructive symptoms can also benefit from suppressive therapy. However, the rate of reduction in size of the gland is generally slow and a quick result should not be expected. In a series, all four patients seen received hormone therapy yet failed to achieve significant reduction in size of their lingual thyroid and eventually underwent surgical excision. ${ }^{63}$ It has also been recommended that all asymptomatic euthyroid patients should be given exogenous thyroid hormone to prevent a state of hypothyroidism which eventually develops in most patients. ${ }^{63}$ In addition, it prevents progressive growth of the mass and possible malignant transformation. ${ }^{75}$

Surgical intervention is indicated when severe obstructive symptoms, bleeding, ulceration, cystic 
degeneration and malignancy occur. ${ }^{2,45}$ It is important to determine the presence of a normally located thyroid gland before removal of the ectopic tissue to avoid hypothyroidism. Excision of a lingual thyroid is usually carried out by the trans-oral route. It is best for small lesions because of the limited exposure it provides. In bigger lesions, exposure can be improved by adopting the midline mandibulotomy and tongue splitting technique. The drawback of this technique is the residual scar in the lower lip and mental region. To avoid this, a lower lip de-gloving technique without lip incision has been recommended. ${ }^{76}$ Control of bleeding is another challenge associated with the trans-oral approach. To address this, feeding vessels such as the bilateral lingual arteries may need to be identified and ligated prior to excision, ${ }^{63}$ although risk of tongue necrosis is increased with this method. Excision of the gland endoscopically using $\mathrm{CO}_{2}$ laser or harmonic scalpel has been done successfully with lesser bleeding and post-operative morbidity. ${ }^{63,77,78}$ Terries et al reported the removal of an obstructive lingual thyroid using a minimally invasive trans-oral procedure that incorporates Harmonic technology and high resolution endoscopy without external incision on an out-patient basis. ${ }^{78}$ Large swellings are often removed surgically through lateral pharyngotomy, suprahyoid or transhyoid approaches. These techniques offer good exposure and control of bleeding is easier. They are, however, associated with higher risk of injury to vital structures and fistula formation between neck skin and the oropharynx. ${ }^{76}$

The ectopic gland may be the only functional thyroid and complete excision is followed by lifelong hormone replacement. Procedures described to retain some degree of thyroid function in the patients are the transposition of the ectopic thyroid with a vascular pedicle flap into the muscle space at the floor of the mouth ${ }^{76}$ or the lateral pharyngeal wall, ${ }^{79}$ auto-transplantation of thyroid tissue into the anterior rectus sheath or under the strap muscles ${ }^{80}$ and partial trans-oral endoscopic excision in small and anterior lesions. ${ }^{81}$ The transposition technique enables satisfactory long-term post-operative thyroid function, while $70 \%$ of patients will require exogenous thyroid hormone replacement following auto-transplantation. ${ }^{76,63}$ Control of intra-operative bleeding is a challenge in partial trans-oral ablation and substitutive hormone treatment may be required to preserve euthyroid status and avoid recurrence of the mass following the procedure. ${ }^{81}$

Ectopic thyroid in the antero-medial and lateral neck regions may require surgical excision for cosmetic reasons or when the swelling is symptomatic and does not respond to replacement therapy. Surgery is also indicated if malignancy is suspected. Surgical excision of ectopic intra-tracheal thyroid is indicated if the size of the gland is large and causing pressure symptoms or in cases of histological malignancy. The gland can be removed via the open cricoid procedure or the endoscopic laser-assisted approach. ${ }^{82}$ Symptomatic intra-thoracic ectopic goitres are usually excised surgically via thoracotomy or sternotomy. Thoracoscopic excision, including robotic resection, has also been reported. ${ }^{68,83}$ Intra-cardiac thyroid mass is surgically excised under standard cardio-pulmonary by-pass, ${ }^{15}$ while sub-diaphragmatic intra-abdominal ectopic thyroid swelling is resected via laparotomy. After surgical resection, the ectopic thyroid tissue is sent for histological diagnosis. When diagnosis of ectopic thyroid is made post-operatively, patients are further evaluated for the presence of eutopic or other ectopic thyroid tissue and thyroid function. Further treatment is determined by the outcome of the investigations.

Radioactive iodine 131 therapy is an alternative to surgical ablation. However, shrinkage of thyroid tissue is not consistent following this mode of treatment. It is indicated in patients who are not fit for surgery, in those who refused operation and where surgical resection is not feasible due to anatomical difficulties. ${ }^{63,84}$ It is contraindicated in pregnant women and avoided in younger paediatric patients. Other disadvantages include slow response to medication, fibrosis, radiation-induced tracheitis and dependence on life-long thyroid hormone replacement. ${ }^{45,63,67}$ Treatment of ectopic thyroid with features of hyperthyroidism can be achieved by anti-thyroid medication or surgical excision. Radioactive iodine therapy can be used as well, especially in patients who do not respond satisfactorily to anti-thyroid drugs. ${ }^{40}$ Life-long replacement therapy following surgical excision or radioiodine ablation of thyroid tissue may not be readily acceptable or affordable in some developing countries where patients are relatively poor. It is important to bear this in mind 
when treating patients in such communities. Surgical procedures like transposition of the ectopic thyroid tissue should be considered in patients who may not comply with life-long replacement medication.

\section{CONCLUSION}

Ectopic thyroid remains a rare disease. Although the cause is not fully known, genetic factors have been associated with thyroid gland morphogenesis and differentiation. So far, no mutation in known genes has been associated with human thyroid ectopy. Different pathological changes that affect normal eutopic thyroid can occur in the ectopic tissue. The majority are asymptomatic; however, symptoms may arise following enlargement of the gland during periods of stress. Patients may present insidiously or as an emergency. Radionuclide thyroid imaging, ultrasonography, CT scan, MRI, biopsy and thyroid function tests are the main diagnostic tools. Surgical excision is often required as treatment for this condition. Employing a minimally invasive technique has made it possible to excise lingual thyroid as a day procedure.

\section{REFERENCES}

1. Felice MD, Lauro RD, 2004 Thyroid Development and its disorders: Genetic and molecular mechanisms. Endocrine Reviews 25: 722-746.

2. Yoon JS, Won KC, Cho IH, Lee JT, Lee HW, 2007 Clinical characteristics of ectopic thyroid in Korea. Thyroid 17: 1117-1121.

3. Sauk JJ, 1970 Ectopic lingual thyroid. J Pathol 102: 239-245.

4. Radkowski D, Arnold J, Healy G, et al, 1991 Thyroglossal duct remnant. Pre-operative evaluation and management. Arch Otolaryngol Head Neck Surg 117: 1378-1381.

5. Batsakis JG, El-Naggar AK, Luna MA, 1996 Thyroid gland ectopias. Am Otol Rhinol Laryngol 105: 996-1000.

6. Hickman W, 1869 Congenital tumor of the base of the tongue, pressing down the epiglottis on the larynx and causing death by suffocation sixteen hours after birth. Trans Pathol Soc Lond 20: 160-161.

7. Hari CK, Brown MJ, Thompson I, 1999 Tall cell variant of papillary carcinoma arising from ectopic thyroid tissue in the trachea. J Laryngol Otol 113: 183-185.

8. Aguirre A, de la Piedro M, Ruiz R, Portilla J, 1991 Ectopic thyroid tissue in the submandibular region. Oral Surg Oral Med Oral Pathol 71: 73-77.

9. Choi JY, Kim JH, 2008 Case of an Ectopic Thyroid Gland at the Lateral Neck Masquerading as a Metastatic Papillary Thyroid Carcinoma. J Korean Med Sci 23: 548-550.
10. Kuffner HA, McCook BM, Swaminatha R, Myers EN, Hunt JL, 2005 Controversial Ectopic Thyroid: A Case Report of Thyroid Tissue in the Axilla and Benign Total Thyroidectomy. Thyroid 15: 1095-1097.

11. Sarin YK, Sharma AK,1993 Ectopic tonsillar thyroid. Indian Pediatr 30: 1461-1462.

12. Rubenfeld S, Joseph UA, Schwartz MR, Weber SC, Jhingran SG, 1988 Ectopic thyroid in the right carotid triangle. Arch Otolaryngol Head Neck Surg 114: 913-915.

13. Tiberti A, Damato B, Hiscott P, Vora J, 2006 Iris Ectopic Thyroid Tissue: Report of a Case. Arch Ophthalmol 124: 1497-1500.

14. Malone Q, Conn J, Gonzales M, Kaye A, Coleman P, 1997 Ectopic pituitary fossa thyroid tissue. J Clin Neurosci 4: 360-363.

15. Comajuan SM, Ayerbe JL, Ferrer BR, et al, 2009 An intracardiac ectopic thyroid mass. Eur J Echocardiogr 10: 704-706.

16. Ozpolat B, Dogan OV, Gökaslan G, Erekul S, Yücel E, 2007 Ectopic thyroid gland on the ascending aorta with a partial pericardial defect: report of a case. Surg Today 37: 486-488.

17. Spinner RJ, Moor KL, Gottfried MR, 1994 Thoracic intrathymic Thyroid. Ann Surg 220: 91-96.

18. Salam MA, 1992 Ectopic thyroid mass adherent to the oesophagus. J Laryngol Otol 106: 746-747.

19. Takahasi T, Ishikura H, Kato H, Tarabe T, Yoshiki T, 1991 Ectopic thyroid follicles in the submucosa of the duodenum. Virchows Arch A pathol Anat Histopathol 418: 547-550.

20. Liang K, Liu JF, Wang YH, Tang GC, Teng LH, Li F, 2010 Ectopic thyroid presenting as a gallbladder mass. Ann R Coll Surg Engl 92: W4-6.

21. Cicek Y, Tasci H, Gokdogan C, Ones S, Goksel S, 1993 Intra-abdominal ectopic thyroid. Br J Surg 80: 316.

22. Evuboglu E, Kapan M, Ipek T, Ersan Y, Oz F, 1999 Ectopic thyroid in the abdomen: report of a case. Surg Today 29: 472-474.

23. Gunqor B, Kebat T, Ozaslan C, Akilli S, 2002 Intraabdominal ectopic thyroid presenting with hyperthyroidism: report of a case. Surg Today 32: 148-150.

24. Ghanem N, Bley Y, Altehoefer C, Högerle S, Langer M, 2003 Ectopic thyroid gland in the Porta Hepatis and Lingua. Thyroid 13: 503-507.

25. Hagiuda J, Kuroda I, Tsukamoto T, 2006 Ectopic thyroid in an adrenal mass: a case report. BMC Urol 6: 18.

26. Roth LM, Miller AW, Talerman AM, 2008 Typical Thyroid-Type Carcinoma Arising in Struma Ovarii: A Report of 4 Cases and Review of the Literature. Int J Gynecol Pathol 27: 496-506.

27. Hoda SA, Huvos AG, 1993 Struma salpingis associated with struma ovarii. Am J Surg Pathol 17: 1187-1189.

28. Yilmaz F, Uzunlar AK, Sogutau N, 2005 Ectopic thyroid tissue in the uterus. Acta Obstet Gynaecol Scand 84: 201-202.

29. Kurman RJ, Prabha AC, 1973 Thyroid and parathyroid 
glands in the vaginal wall: report of a case. Am J Clin Pathol 59: 503-507.

30. Huang TS, Chen HY, 2007 Dual thyroid ectopia with a normally located pretracheal thyroid gland: case report and literature review. Head Neck 29: 885-888.

31. Ibrahim NA, Oludara MA, 2009 Lateral cervical ectopic thyroid masses with eutopic multinodular goiter: an unusual presentation. Hormones (Athens) 8: 150-153.

32. Gillam MP, Kopp P, 2001 Genetic regulation of thyroid development. Curr Opin Pediatr 13: 358-363.

33. Silberschmidt D, Rodriguez-Mallon A, Mithboakar $\mathrm{P}$, et al, $2011 \mathrm{In}$ vivo role of different domains and of phosphorylation in the transcription factor $\mathrm{Nkx} 2-1$. BMC Dev Biol 11: 9.

34. Nitsch R, Di Dato V, di Gennaro A, et al, 2010 Comparative genomics reveals a functional thyroid-specific element in the far upstream region of the PAX8 gene. BMC Genomics 11: 306.

35. Misaki T, Koh T, Shimbo S, Kasagi K, Konishi J, 1992 Dual-site thyroid ectopy in a mother and son. Thyroid 2: 325-327.

36. Alt B, Elsalini OA, Schrumpf P, et al, 2006 Arteries define the position of the thyroid gland during developmental relocalization. Development 136: 3797-3804.

37. Olivieri A, Stazi MA, Mastroiacovo P, et al, 2002 A population-based study on the frequency of additional congenital malformations in infants with congenital hypothyroidism: data from the Italian Registry for Congenital Hypothyroidism (1991-1998). J Clin Endocrinol Metab 87: 557-562.

38. Harach HR, 1998 Ectopic thyroid tissue adjacent to the gallbladder. Histopathology 32: 90-91.

39. Al-Jurayyan NA, El-Desouki MI, 1997 Transient lodine Organification Defect in Infants With Ectopic Thyroid Glands. Clin Nucl Med 22: 13-16.

40. Kumar R, Gupta R, Bal CS, Khullar S, Malhotra A, 2000 Thyrotoxicosis in a patient with submandibular thyroid. Thyroid 10: 363-365.

41. Sung YM, Lee KS, Han J, Cho EY, 2008 Intratracheal ectopic thyroid tissue with adenomatous hyperplasia in a pregnant woman. Am J Roentgenol 190: 161-163.

42. Wein RO, Norante JD, 2001 Hashimoto's thyroiditis within ectopic thyroid gland mimicking the presentation of thyroglossal duct cyst. Otolaryngol Head Neck Surg 125: 274-276.

43. Dossing H, Jorgensen KE, Jorgensen EO, Krogdahl A, Hegedus L, 1999 Recurrent Pregnancy-Related Upper Airway Obstruction Caused by Intratracheal Ectopic Thyroid Tissue. Thyroid 9: 955-958.

44. Rasmussen NG, Hornnes PJ, Hegedus L, 1989 Ultrasonographically determined thyroid size in pregnancy and post partum: The goitrogenic effect of pregnancy. Am J Obstet Gynecol 160: 1216-1220.

45. Talwan N, Mohan S, Ravi B, Andley M, Kumar A, 2008 Lithium-induced enlargement of a lingual thyroid. Singapore Med J 49: 354.
46. Larochelle D, Arcand P, Belzile M, Gagnon NB, 1979 Ectopic thyroid tissue - a review of the literature. $\mathrm{J}$ Otolaryngol 8: 523-530.

47. Willi SM, Moshang T Jr, 1991 Diagnostic dilemmas. Result of screening tests for congenital hypothyroidism. Ped Clin North Am 38: 555-566.

48. Kalan A, Tariq M, 1999 Lingual thyroid gland: clinical evaluation and comprehensive management. Ear Nose Throat J 78: 340-341, 345-349.

49. El-Desouki M, Al-Jurayyan N, Al-Nuaim A, et al, 1995 Thyroid scintigraphy and perchlorate discharge test in the diagnosis of congenital hypothyroidism. Eur J Nucl Med 22: 1005-1008.

50. Tojo K, 1998 Lingual Thyroid Presenting as Acquired Hypothyroidism in the Adulthood. Inter Med 37: 381-384.

51. Shakir KM, 1982 Lingual thyroid associated with hypothyroidism and lymphomatous thyroiditis: a case report. Mil Med 147: 591.

52. Kamijo K, 2005 Lingual Thyroid Associated with Graves' Disease Graves' Ophtalmopathy. Thyroid 15: 1407-1408.

53. Basaria S, Cooper DS, 1999 Graves' Disease and Recurrent Ectopic Thyroid Tissue. Thyroid 9: 1261-1264.

54. Yamauchi M, Inoue D, Sato H, 1999 A case of ectopic thyroid in lateral neck associated with Graves' disease. Endocr J 46: 731-734.

55. Wang YJ, Chu PY, Tai SK, 2010 Ectopic thyroid papillary carcinoma presenting as bilateral neck masses. J Chin Med Assoc 73: 219-221.

56. Tucci J, Rulli F, 1999 Follicular Carcinoma in ectopic thyroid gland. A case report. G Chir 20: 97-99.

57. Hari CK, Kumar M, Abo-Khatwa MM, Adams-Williams J, Zeitoun H, 2009 Follicular variant of papillary carcinoma arising from lingual thyroid. Ear Nose Throat J 88: E7.

58. Mishriki YY, Lane BP, Lozowski MS, Epstein H, 1983 Hurthle cell tumour arising in the mediastinal ectopic thyroid and diagnosed by fine needle aspiration: light microscopic and ultrastructural features. Acta Cytol 27: 188-192.

59. Yaday S, Singh I, Singh J, Aggarwal N, 2008 Medullary carcinoma in a lingual thyroid. Singapore Med J 49: 251-253.

60. Jarvis JF, 1969 Lingual Thyroid: a report of three cases and discussions. S Afr Med J 43: 8-12.

61. Ranaldi R, Morichetti D, Goteri D, Martino A, 2009 Immature teratoma of the mediastinum arising in ectopic thyroid tissue; a case report. Anal Quant Cytol Histol 31: 233-238.

62. Demirag F, Cakir E, Aydin E, Kaya S, Akyurek N, 2009 Ectopic primary B cell lymphoma of the thyroid presenting as an anterior mediastinal mass. A case report. Acta Chir Belg 109: 802-804.

63. Rahbar R, Yoon MJ, Connolly LP, et al, 2008 Lingual Thyroid in Children: A Rare Clinical Entity. Laryngoscope 118: 1174-1179.

64. Barnes TW, Olsen KD, Morgenthaler TI, 2004 Obstruc- 
tive lingual thyroid causing sleep apnoea: a case report and review of the literature. Sleep Med 5: 605-607.

65. Koch CA, Picken C, Clement SC, Azumi N, Sarlis NJ, 2000 Ectopic Lingual Thyroid: an otolaryngologic emergency beyond childhood. Thyroid 10: 511-514.

66. Mussak EN, Kacker A, 2007 Surgical and medical management of midline ectopic thyroid. Otolaryngol Head Neck Surg 136:870-872.

67. Yang Y, Li Q, Qu J,et al, 2010 Ectopic Intratracheal Thyroid. South Med J 103: 467-470.

68. Shah BC, Ravichand CS, Juluri S, Agarwal A, Pramesh CS, Mistry RC, 2007 Ectopic thyroid cancer. Ann Thorac Cardiovasc Surg 13: 122-124.

69. Aklotun C, Demir H, Berk F, Metin KK, 2001 Diagnosis of Complete Ectopic Lingual Thyroid with Tc-99m Pertechnetate Scintigraphy. Clin Nucl Med 26: 933-935.

70. Intenzo CM, dePapp AE, Jabbour S, Miller JL, Kim SM, Capuzzi DM, 2003 Scintigraphic manifestations of thyrotoxicosis. Radiographics 23: 857-869.

71. Ohnishi H, Sato H, Noda H, Inomata H, Sasaki N, 2003 Color Doppler ultrasonography: diagnosis of ectopic thyroid gland in patients with congenital hypothyroidism caused by thyroid dysgenesis. J Clin Endocrinol Metab 88: 5145-5149.

72. Lim-Dunham JE, Feinstein KA, Yousefzadeh DK, BenAmi T, 1995 Sonographic demonstration of a normal thyroid gland excludes ectopic thyroid in patients with thyroglossal duct cyst. Am J Roentgenol 164: 1489-91.

73. Wong RJ, Cunningham MJ, Curtin HD, 1998 Cervical ectopic thyroid. Am J Otolaryngol 19: 397-400.

74. Djemli A, Fillion M, Belgoudi J, et al, 2004 Twenty years later: a reevaluation of the contribution of plasma thyroglobulin to the diagnosis of thyroid dysgenesis in infants with congenital hypothyroidism. Clin Biochem 37:818-822.

75. Kansal P, Sakati N, Rifai A, Woodhouse N, 1987 Lingual thyroid. Diagnosis and treatment. Arch Intern Med 147: 2046-2048.

76. Wu ZX, Zheng LW, Dong YJ, Li ZB, Zhang WF, Zhao YF, 2008 Modified approach for lingual thyroid transposition: report of two cases. Thyroid 18: 465-468.

77. Hafidh MA, Sheahan P, Khan NA, Colreavy M, Timon C, 2004 Role of CO2 laser in the management of obstructive ectopic lingual thyroids. J Laryngol Otol 118: 807-809.

78. Terris DJ, Seybt MW, Vaughters RB, 2010 A new minimally invasive lingual thyroidectomy technique. Thyroid 20: 1367-1369.

79. Rojananin S, Ungkanont K, 1999 Transposition of the lingual thyroid: A new alternative technique. Head Neck 21: 480-483.

80. Al-Samarrai AY, Crankson SJ, Al-Jobori A, 1988 Autotransplantation of lingual thyroid into the neck. Br J Surg 75: 287.

81. Toso A, Colombani F, Averono G, Aluffi P, Pia F, 2009 Lingual thyroid causing dysphagia and dyspnoea. Case reports and review of the literature. Acta Otorhinolaryngol Ital 29: 213-217.

82. Yang Y, Li Q, Qu J, 2010 Ectopic Intratracheal Thyroid. South Med J 103: 467-470.

83. Bodner J, Fish J, Lottersberger AC, Wetscher G, Schmid T, 2005 Robotic Resection of an Ectopic Goiter in the Mediastinum. Surg Laparosc Endosc Percutan Tech 15: 249-251.

84. Iglesias P, Olmos-García R, Riva B, Díez JJ, 2008 Iodine 131 and Lingual Thyroid. J Clin Endocrinol Metab 93: 4198-4199. 